
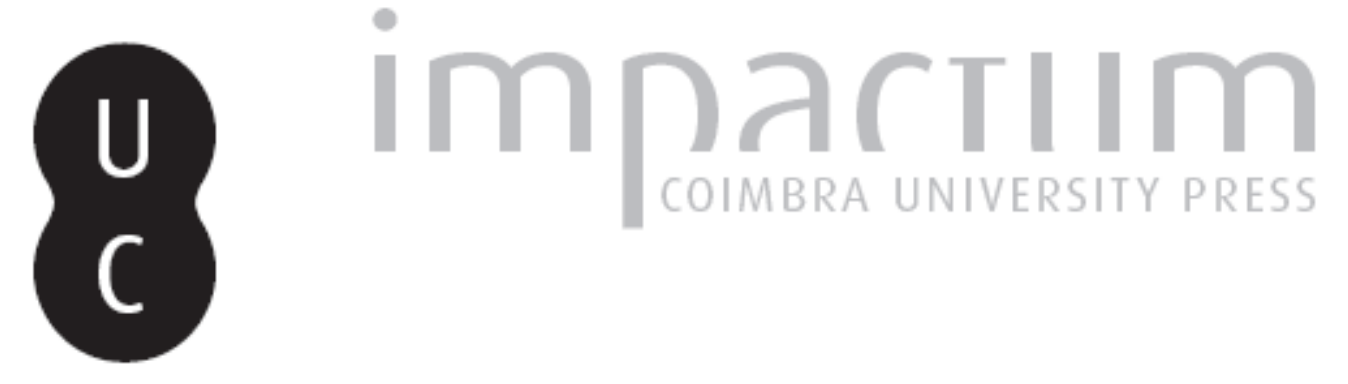

\title{
Higino, um mitógrafo latino em tradução IX: o mito de Pasífae
}
Autor(es):
Matias, Mariana Montalvão Publicado por: $\begin{aligned} & \text { Associação Portuguesa de Estudos Clássicos; Instituto de Estudos } \\ & \text { Clássicos }\end{aligned}$

URL persistente:

URI:http://hdl.handle.net/10316.2/30382

DOI:

DOI:http://dx.doi.org/10.14195/0872-2110_53_7

Accessed : $\quad$ 26-Apr-2023 13:00:19

A navegação consulta e descarregamento dos títulos inseridos nas Bibliotecas Digitais UC Digitalis, UC Pombalina e UC Impactum, pressupõem a aceitação plena e sem reservas dos Termos e Condições de Uso destas Bibliotecas Digitais, disponíveis em https://digitalis.uc.pt/pt-pt/termos.

Conforme exposto nos referidos Termos e Condições de Uso, o descarregamento de títulos de acesso restrito requer uma licença válida de autorização devendo o utilizador aceder ao(s) documento(s) a partir de um endereço de IP da instituição detentora da supramencionada licença.

Ao utilizador é apenas permitido o descarregamento para uso pessoal, pelo que o emprego do(s) título(s) descarregado(s) para outro fim, designadamente comercial, carece de autorização do respetivo autor ou editor da obra.

Na medida em que todas as obras da UC Digitalis se encontram protegidas pelo Código do Direito de Autor e Direitos Conexos e demais legislação aplicável, toda a cópia, parcial ou total, deste documento, nos casos em que é legalmente admitida, deverá conter ou fazer-se acompanhar por este aviso.

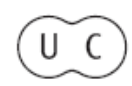




\section{Boletim de \\ Estudos Clássicos}

Associação Portuguesa de Estudos Clássicos Instituto de Estudos Clássicos

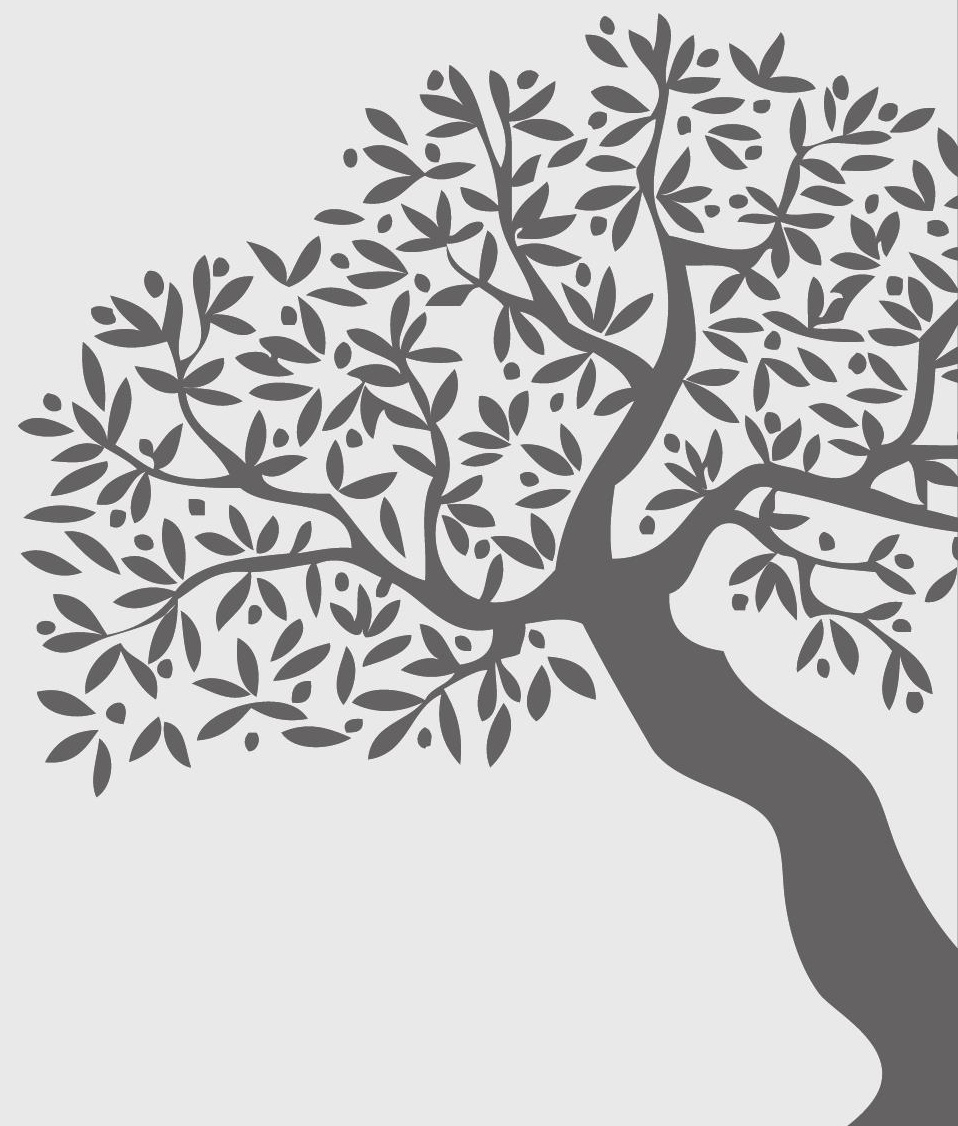

Coimbra

Junho de 2010 


\section{Higino, um MitógRafo LaTino EM TRAdUÇÃo IX. O Mito de Pasífae}

Para onde vais alma? Porquê este louco amor pelas clareiras?
Reconheço a culpa fatal de minha desgraçada mãe.

Séneca, Fedra

No passado dia 5 de Maio, o grupo Thíasos estreou a sua última produção - Hipólito de Eurípides - no Museu Nacional Machado de Castro em Coimbra, baseada na tradução de Frederico Lourenço. Quem lá esteve pôde, apesar do frio que se fez sentir, desfrutar de uma noite mágica de teatro. Para a construção do intenso pathos muito contribuíram a coerência do elenco, numa encenação criativa, uma sonoplastia e luminotecnia originais e elegantes figurinos. O pátio exterior do museu foi palco de uma representação viva e bem conseguida do mito de Fedra e da paixão adúltera e (quase) incestuosa pelo enteado Hipólito ${ }^{1}$. Uma mulher vítima, na perspectiva euripidiana, da vingança da deusa Afrodite, mas que carrega consigo o peso de uma hereditariedade terrível herdada de sua mãe, Pasífae. Segundo a lenda, esta nutrira um amor avassalador por um touro e dessa união terá nascido o Minotauro, criatura híbrida, com corpo de homem e cabeça de touro. Corre no sangue destas mulheres de Creta a atracção pelo amores impossíveis e contra naturam.

Higino, mitógrafo latino, compilador de fabulae mitológicas, dedica a fábula XL, que aqui apresentamos juntamente com a sua tradução e exploração didáctica, ao mito de Pasífae, mãe de Fedra, e à paixão monstruosa desta pelo Minotauro cretense.

\section{PASIPHAE}

1. Pasiphae Solis filia uxor Minois sacra deae Veneris per aliquot annos non fecerat. ob id Venus amorem infandum illi obiecit, ut taurum quem †ipsa

1 Ao mito de Hipólito dedicou Higino a fábula XLVII, cujo texto original, tradução e exploração didáctica apresentámos em "Higino, um mitógrafo latino em tradução III. O mito de Hipólito” BEC 47 (Junho 2007) 57-60. 
amabat alia $\dagger$ amaret. 2. in hoc Daedalus exsul cum uenisset, petiit ab ea auxilium. is ei uaccam ligneam fecit et uerae uaccae corium induxit, in qua illa cum tauro concubuit; ex quo compressu Minotaurum peperit capite bubulo parte inferiore humana. 3. tunc Daedalus Minotauro labyrinthum inextricabili exitu fecit, in quo est conclusus. 4. Minos re cognita Daedalum in custodiam coniecit, at Pasiphae eum uinculis liberauit; itaque Daedalus pennas sibi et Icaro filio suo fecit et accommodauit, et inde auolarunt. Icarus altius uolans, a sole cera calefacta, decidit in mare quod ex eo Icarium pelagus est appellatum. Daedalus peruolauit ad regem Cocalum in insulam Siciliam. 5. alii dicunt; Theseus cum Minotaurum occidit, Daedalum Athenas in patriam suam reduxit.

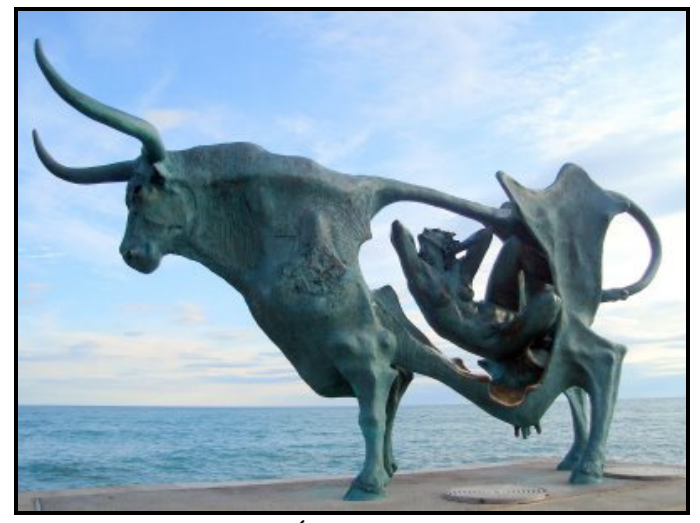

Pasifae, de Óscar Estruga (1996),

escultura em Vilanova i la Geltrú, província de Barcelona

\section{PASÍFAE}

1. Pasífae, filha do Sol, esposa de Minos, não fazia sacrifícios em honra da deusa Vénus durante alguns anos. Por essa razão, Vénus infundiu-lhe um amor monstruoso, que amasse um touro que $<$ Neptuno tinha enviado $>2$. 2 . Nessa altura, Dédalo tinha chegado exilado, e ela pediu-lhe ajuda. Ele fabricou-lhe uma vaca de madeira e revestiu-a com uma pele de vaca

2 Estamos perante uma corrupção textual de difícil solução. Seguimos a sugestão de H. I. Rose (Hygini Fabulae, Leiden, 1963), edição que tem servido de base ao nosso trabalho, de forma a completar a frase: < ut taurum quem Neptunus miserat amaret $>$. 
verdadeira, dentro da qual Pasífae teve relações com o touro; desta união deu à luz o Minotauro, com cabeça de touro e corpo de homem. 3. Então Dédalo construiu para o Minotauro um labirinto com uma saída inextricável, dentro do qual o encerrou. 4. Minos, ao saber o que se passava, prendeu Dédalo, mas Pasífae libertou-o das correntes. Assim Dédalo construiu e adaptou para si e para o seu filho Ícaro umas asas, e de lá fugiram a voar. Ícaro, voando mais alto, e porque a cera aqueceu com o sol, caiu ao mar que, por esse motivo, se chama Icário. Dédalo voou até à ilha da Sicília, para junto do rei Cócalo. 5. Outros afirmam que, quando Teseu matou o Minotauro, trouxe Dédalo de volta a Atenas, a sua pátria.

\section{Higino e a tradição mitológica: Pasífae e o touro}

Pasífae ${ }^{3}$ era filha de Hélios, deus do Sol, e de Perseide (ou Perseida), a Oceânide, que geraram além dela Eetes, rei da Cólquida, e a feiticeira Circe. Casou-se com Minos, filho de Zeus e de Europa, com quem teve os filhos Androgeu, Ariadne, Fedra, Glauco, e Catreu.

Minos foi o sucessor de Astérion no trono de Creta, mas os seus irmãos, Sarpédon e Radamanto, não conformados com a decisão, quiseram disputar o poder. Para provar que Creta lhe pertencia por vontade divina, Minos afirmou que os deuses lhe concederiam qualquer coisa que ele desejasse. Pediu assim a Poséidon que fizesse sair do mar Egeu um touro, prometendo-lhe que depois sacrificaria o animal em sua honra. O deus dos mares enviou um magnífico touro branco. Perante essa demonstração de legitimidade divina, os irmãos de Minos reconheceram-no como soberano da ilha.

Minos, porém, atraiu a vingança e a cólera de Poséidon ao recusar-lhe o sacrifício do touro como havia prometido inicialmente, tornando-o parte do seu rebanho e imolando, no seu lugar, um animal comum. Furioso com tal desobediência, o deus transformou o touro num animal enraivecido e indomável que assustava todos os habitantes de Creta. Mais tarde, inspirou na esposa do soberano, Pasífae, uma paixão avassaladora pelo animal. Dizia-se também que este castigo teria sido infligido à esposa de Minos por Afrodite, pelo facto de aquela ter desprezado o culto da deusa; ou então que seria uma vingança da deusa do amor pela ofensa que Hélios, pai de Pasífae, lhe fizera ao revelar a Hefestos a sua infidelidade com Ares.

${ }^{3}$ Pasífae vem do grego Пaбıфán, Pasipháē, "a que ilumina tudo". 
Desejando saciar a sua paixão, Pasífae pede ajuda ao engenhoso Dédalo que lhe fabrica uma vaca de madeira tão perfeita e credível que engana o próprio touro. Esconde-se dentro do simulacro e assim consegue consumar o seu amor, nascendo dessa união monstruosa o Minotauro ${ }^{4}$, uma criatura híbrida metade touro, metade homem. Minos, ao saber da traição da esposa, encarrega Dédalo, o engenhoso arquitecto, de construir um edifício especial onde o monstro fosse encarcerado: surge o Labirinto. Mas, por ter traído o rei, ao favorecer os amores de Ariadne e Teseu, Minos impediu que Dédalo saísse de Creta e ordenou que também ele fosse encarcerado no Labirinto juntamente com o seu filho Ícaro. Porém, conseguiram ambos escapar graças às asas que Dédalo fabricou e que ambos colaram aos ombros com cera. O pai recomendou ao filho que, ao voar, não se aproximasse demasiado do sol. Ícaro, porém, entusiasmado, não deu ouvidos aos conselhos paternos e subiu tão alto que os raios de sol derreteram a cera das asas. O infeliz precipita-se assim no mar que a partir de então tomou o seu nome: mar Icário.

Quanto a Pasífae, diz-se que era muito ciumenta e que, para impedir que o marido se unisse a outras mulheres, e para se vingar das suas repetidas infidelidades, lhe lançou uma maldição: todas as mulheres que o amassem morreriam, devoradas por serpentes e escorpiões que ele próprio arremessaria ou, segundo outra versão, ejacularia. Foi Prócris, princesa ateniense, que o libertou do feitiço, dando-lhe uma erva mágica que recebera de Circe.

Como tivemos oportunidade de verificar no nosso artigo dedicado ao mito de Teseu e Ariadne ${ }^{5}$, apesar de a lenda do Labirinto ser um dos temas mais tratados ao longo de todos os tempos, quer de forma independente, quer através da ligação que estabelece com os seus mitemas (Dédalo, Minotauro, Teseu), é efectivamente escasso o relevo que os autores da época arcaica e clássica lhe atribuem. As alusões e referências breves provam que a lenda era conhecida, mas o mito só aparece sistematizado em autores gregos e romanos tardios.

Em relação a Pasífae, figura que dá título à fábula XL de Higino, e à sua relação com o touro e nascimento do Minotauro, encontramos, num texto

${ }^{4} \mathrm{O}$ nome pessoal do monstro seria Astério, mas surge geralmente designado por Minotauro.

$5 \mathrm{O}$ mito de Teseu, do Minotauro e de Ariadne explora-o Higino nas fábulas XLII e XLIII. Vide "Higino, um mitógrafo latino em tradução VI. O mito de Teseu e Ariadne" BEC 50 (Dezembro 2008) 35-44. 
atribuído ao Catálogo das Mulheres de Hesíodo, de que apenas nos restam fragmentos, alusões ao nascimento do Minotauro (fr. 145 Merkelbach-West), que é dado como filho de Minos e não do touro:

Ela, grávida de Minos, deu à luz um filho robusto, maravilha de se ver: igual ao do homem se estendia o corpo até aos pés, mas para cima erguia-se uma cabeça de touro. ${ }^{6}$

De entre os autores gregos do período helenístico, destacamos - a propósito dos coros, danças e ofertas de coroas em honra de Cípris aquando do regresso de Teseu de Creta - a referência a Pasífae no Hino a Delos de Calímaco (vv. 310-313).

Já na segunda metade do séc. V a.C. Eurípides trata o tema do Labirinto, do Minotauro e de Teseu em diversas ocasiões. Veja-se, a título de exemplo, a referência que, em Héracles, Teseu faz à sua vitória sobre o Minotauro (vv. 1326-1328). Julga-se que, das peças perdidas, Cretenses provavelmente se relacionaria com o nascimento do Minotauro (frs. 471-472 $\mathrm{N}^{2}$ ), e que a tragédia Teseu parece ter dramatizado a morte do monstro e a subsequente fuga do herói (frs. 381-390 N²; P. Oxy. 27. 2461). Em Hipólito, drama que versa sobre os amores terríveis da filha de Pasífae pelo enteado, é Fedra que alude à herança genética que a sua figura carrega (vv. 337-339):

\section{FEDRA}

Pobre mãe, por que amor te foste apaixonar!

AMA

Pelo touro, filha? Mas porque dizes isso?

\section{FEDRA}

E tu, desgraçada irmã, esposa de Dioniso!

AMA

O que te deu, filha? Estás a insultar os teus parentes?

FEDRA

E a terceira desgraçada sou eu, visto que estou perdida. ${ }^{7}$

6 Tradução de José Ribeiro Ferreira.

7 Tradução de Frederico Lourenço. Hipólito de Eurípides. Introdução e

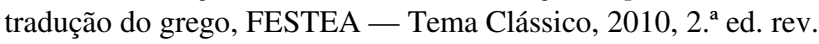


Até ao séc. V encontramos apenas breves referências ou alusões a Pasífae e ao touro. A sua estória ganha maior destaque em autores gregos e latinos posteriores, como Diodoro Sículo (4. 60 sqq.), Apolodoro (3.1.2-4), ou Plutarco (Agis, 9).

São, contudo, os grandes poetas da era augusta que dedicam uma maior atenção a esta personagem mitológica tão fascinante. Em Eneida (6. 14-33), Virgílio trata o crudelis amor de Pasífae pelo touro, o nascimento do híbrido Minotauro - nas palavras do Mantuano, Veneris monimenta nefandae -, a construção do labirinto, a fuga de Dédalo e a hybris funesta de Ícaro. Na sua Bucólica 6 (46 sqq.) também nos apresenta uma versão delicada e compassiva do mito: A! uirgo infelix, quae te dementia cepit! (v. 47). Uma Pasífae que se tomou loucamente de amores pelo touro branco e cujo sentimento é comparado ao das filhas de Preto, rei de Argos, que, enlouquecidas, julgavam ser vacas, pastando e mugindo pelos campos fora: A! uirgo infelix, tu nunc in montibus erras (v. 52).

Também Ovídio em vários momentos das suas Metamorfoses (8. 136 sqq.; 9.736 sqq.; 15. 497-505) se reporta ao imundo adultério de Pasífae, à construção do labirinto por Dédalo e à funesta ousadia de Ícaro. Em Heroides 4, na carta imaginária da madrasta ao enteado Hipólito ${ }^{8}$, Fedra encara a sua paixão adúltera como a consequência da hereditariedade funesta de um genus iniciado por Europa, seduzida por Júpiter sob a forma de touro. Pasífae, vítima também do amor por um touro, gerou e deu à luz o fruto da sua vergonha (vv. 53-58).

Nem na sua Ars Amatoria Ovídio ficou indiferente aos amores monstruosos de Pasífae pelo belo animal branco (1. 289-327). Com o colorido próprio da poesia ovidiana, o poeta transporta-nos para os vales do Ida por onde pastava o amado de Pasífae. Sempre ciumenta, a rainha olhava com ódio para as outras vacas: Inuida formosas oderat illa boues (v. 296). Quantas vezes ela mesma cortava os mais tenros caules e ervas para lhe dar, e pedia aos deuses que a convertessem em Europa ou em Io: Et modo se Europen fieri, modo postulat Io ,/ altera quod bos est, altera uecta boue (vv. 323-4).

8 Heroides IV terá sido o texto lírico que maior influência exerceu na composição da Fedra senequiana. A expressividade lírica de Ovídio sempre inspirou a produção trágica do autor latino. 
Também Séneca, o maior tragediógrafo latino, na sua abordagem dos amores da esposa de Teseu, alude ao carácter genético da physis das mulheres de Creta:

Nenhuma filha de Minos

viveu um amor são, sempre ligada à perversidade. (vv. 127-128)

Terá o mundo de ouvir falar de estranhos prodígios, terá a natureza de perverter as suas próprias leis, sempre que uma mulher de Creta amar? (vv. 175-177) ${ }^{9}$

O mitógrafo latino parece ter tido conhecimento de alguns dos textos que referimos, pois a fábula XL segue a versão do mito em que a paixão pelo touro é encarada como castigo da deusa do Amor. Higino relata a chegada de Dédalo a Creta, a construção da vaca de madeira, a união monstruosa de Pasífae com o touro, o nascimento do Minotauro e a edificação do Labirinto por Dédalo, elementos bem conhecidos do mito. Refere também a fuga de Dédalo e Ícaro do Labirinto. O castigo que este último sofreu por não seguir os conselhos do pai, pela sua hybris, também não é esquecido pelo mitógrafo que termina a sua fábula com a explicação etiológica do nome geográfico do mar Icário.

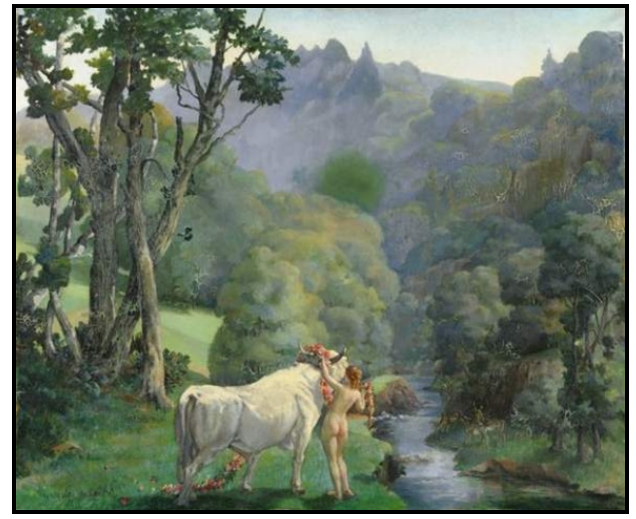

Blanche Lepaitre de Christen, Pasiphae (1931)

9 Tradução de Ana Alexandra Alves de Sousa e Carla Soares, Fedra, introdução e notas, Lisboa, Edições 70, 2003. 


\section{Tópicos de exploração didáctica}

Sintaxe:

(1) Complementos circunstanciais de lugar: 'para onde': in insulam Siciliam; in patriam suam; ad regem Cocalum; Athenas (simples acusativo antes de nomes próprios de cidades ou ilhas pequenas);

(2) Complemento circunstancial de tempo 'duração da acção': per + acusativo (per aliquot annos);

(3) Complemento circunstancial de causa: construção de $o b$ +acusativo (ob id);

(4) Oração subordinada temporal: cum Minotaurum occidit;

(5) Oração subordinada relativa: quod ex eo Icarium pelagus est appellatum;

(6) Oração subordinada final de $u t+$ conjuntivo: ut taurum amaret;

(7) Oração temporal-causal de cum + conjuntivo: cum uenisset;

(8) Ablativo absoluto (re cognita);

(9) Sintaxe de peto, -is, -ere, -iui, -itum com $a$ ou $a b+$ ablativo (petiit ab ea auxilium);

(10) Sintaxe de concumbo, -is, -ere, -cubui, cubitum com cum + ablativo (cum tauro concubuit);

\section{Morfologia:}

(1) Substantivos de flexão greco-latina (Pasiphae; Minois);

(2) Pronome demonstrativo is, ea, id;

(3) Pronome demonstrativo ille, illa, illud;

(4) Pronome demonstrativo hic, haec, hoc;

(5) Pronome relativo qui, quae, quod;

(6) Pretérito perfeito (obiecit; fecit; induxit; liberauit) e pretérito maisque-perfeito do modo indicativo (fecerat);

(7) Pretérito imperfeito (amaret) e mais-que-perfeito do modo conjuntivo (uenisset);

(8) Compostos de duco (induxit; reduxit) e de volo (auolarunt; peruolauit);

(9) Verbos defectivos (aiunt);

(10) Graus dos advérbios: o comparativo em - us (altius). 